\title{
Solid Phase Microextraction
}

National Cancer Institute

\section{Source}

National Cancer Institute. Solid Phase Microextraction. NCI Thesaurus. Code C129962.

A sampling technique that uses a polymer-coated fiber to absorb to directly extract and concentrate an analyte from a fluid. 